\title{
Rancang Bangun Aplikasi Media Pembelajaran Bahasa Inggris Pronoun, Tobe, dan Tenses Berbasis Android
}

\author{
Sri Rahayu ${ }^{1}$, Reski Ramadhani ${ }^{2}$, Nirwan Nurdin Rhamdani ${ }^{3}$ \\ Jurnal Algoritma \\ Institut Teknologi Garut \\ J1. Mayor Syamsu No. 1 Jayaraga Garut 44151 Indonesia \\ Email: jurnal@itg.ac.id \\ ${ }^{1}$ srirahayu@itg.ac.id \\ ${ }^{2}$ reski_ramadhani@itg.ac.id \\ 31606080@sttgarut.ac.id
}

\begin{abstract}
Abstrak - Bahasa Inggris ialah bahasa yang sebagian besar digunakan didunia, sehingga Bahasa Inggris dijadikan Bahasa Universal, di tanah air kita sendiri Bahasa Inggris merupakan bahasa yang harus dipelajari, tetapi dalam proses pembelajarannya Bahasa Inggris masih dipelajari dengan metode buku dan papan tulis sehingga banyak murid yang merasa jenuh dan kurang memperhatikannya. Penggunaan media pembelajaran diperlukan untuk menunjang proses belajar supaya lebih efektif dan efisien. Di karenakan hal itu dirancanglah aplikasi pembelajaran berbasis android yang berisi materi-materi Bahasa Inggris. Metode perancangan aplikasi yang dipakai untuk membangun aplikasi ini yaitu Multimedia Development Life Cycle dengan tahapan konsep, desain, pengumpulan material, pemasangan, pengujian, dan distribusi. Penelitian ini menghasilkan aplikasi media pembelajaran berbasis android dengan teori Bahasa Inggris pronoun, tobe, dan tenses. Dengan adanya aplikasi ini maka masyarakat Indonesia bisa mempelajari Bahasa Inggris kapanpun dan dimanapun tanpa adanya batasan waktu.
\end{abstract}

Kata Kunci - Android; Bahasa Inggris; $M D L C$; Pembelajaran.

\section{PENDAHULUAN}

Bahasa Inggris adalah bahasa universal untuk dapat menyambungkan orang-orang dengan negara luar dalam berbagai sudut termasuk sudut pendidikan [1]. Dalam kehidupan zaman sekarang, Bahasa Inggris merupakan bahasa universal. Dengan perkembangan teknologi yang berjalan, setiap orang di negara kita harus mempelajari bahasa Inggris [2]. Bahasa Inggris diperlukan karena pada zaman globalisasi yang mana semua sistem menggunakan bahasa Inggris [3]. Walaupun begitu masih banyak orang di negara kita yang belum menguasai Bahasa Inggris. Proses mengajar yang bersifat konvensional masih di terapkan di banyak sekolah. Teori-teori mengajar dalam bentuk buku masih banyak digunakan. Hal ini menjadikan siswa tidak terlalu tertarik dan kurang bisa menangkap materi yang disampaikan [4]. Oleh karena itu penting untuk dibuatkannya sebuah media pembelajaran yang diharapkan dapat mengganti metode konvensional agar lebih efektif dan efisien ataupun menjadi metode alternatif di luar sekolah untuk belajar Bahasa Inggris.

Materi yang disampaikan oleh guru akan cepat sampai dan mudah diterima secara maksimal oleh siswa jika media dipakai dalam proses belajar [5]. Media pembelajaran adalah sesuatu yang dapat menyampaikan dan menyalurkan informasi dari sumber secara terencana sehingga terciptanya lingkungan yang kondusif dalam belajar, dimana penerimanya dapat melakukan proses belajar secara efektif dan efisien [6]. Dengan dibuatkannya media pembelajaran Bahasa Inggris maka diharapkan orang Indonesia bisa belajar lebih baik 
lagi agar bisa mengusai Bahasa Inggris secara lisan maupun tulisan.

Penelitian ini ditentukan dengan meneliti penelitian yang sudah ada yaitu penelitian yang membahas mengenai aplikasi wudhu dan shalat berbasis android yang sudah dikembangkan, aplikasi ini dapat dibuka dimanapun tanpa batasan apapun dan siapapun serta menjadikan anak agar lebih positif dalam menggunakan smartphone [7]. Penelitian kedua diantaranya menghasilkan membuat sebuah aplikasi berbasis desktop untuk belajar dengan tampilan mudah dimengerti, dan juga ditambahkannya fitur Bahasa Saudi Arabia untuk membedakan dari aplikasi yang sudah diteliti. Anak-anak dapat mengetahui warna, angka, dan huruf dalam tiga bahasa yaitu bahasa Negara kita yaitu Indonesia, Bahasa Universal yaitu Inggris dan Bahasa Saudi Arabia [8]. Penelitian ketiga diantaranya menghasilkan mengenai pengembangan yang bermaksud buat: (1) Menghasilkan aplikasi belajar yang interaktif, layak dipakai, mudah dimengerti dan bisa digunakan untuk belajar secara individu, (2) Untuk mencari tahu kemudahan dari aplikasi belajar yang interaktif pada salah satu mata pelajaran yaitu Bahasa Inggris [9]. Penelitian keempat diantaranya menghasilkan studi yang memiliki tujuan buat: (1) memperoleh aplikasi belajar yang interaktif untuk mata pelajaran Bahasa Inggris teori narasi yang diperuntukan kepada murid Sekolah Menengah Pertama atau disingkat SMP/MTs, (2) Melihat kualitas kepantasan dan daya guna aplikasi belajar yang interaktif untuk mata pelajaran Bahasa Inggris teori narasi yang diperuntukan kepada murid SMP/MTs [10]. Kelima yaitu mengembangkan aplikasi buat belajar prihal prosedur wudu, sholat dan juga dibuatkannya fitur materi tayamum, do'a-do'a yang biasa dipakai sehari-hari dan surat-surat pendek seperti An-Nas dan lain-lain [11].

\section{METODOLOGI PENELITIAN}

Metode pengerjaan yang dipakai yaitu $M D L C$ maka disusunlah diagram Work Breakdown Structure (WBS) untuk menggambarkan tujuan, tahapan dan aktivitas seperti pada gambar 1, diantaranya sebagai berikut:

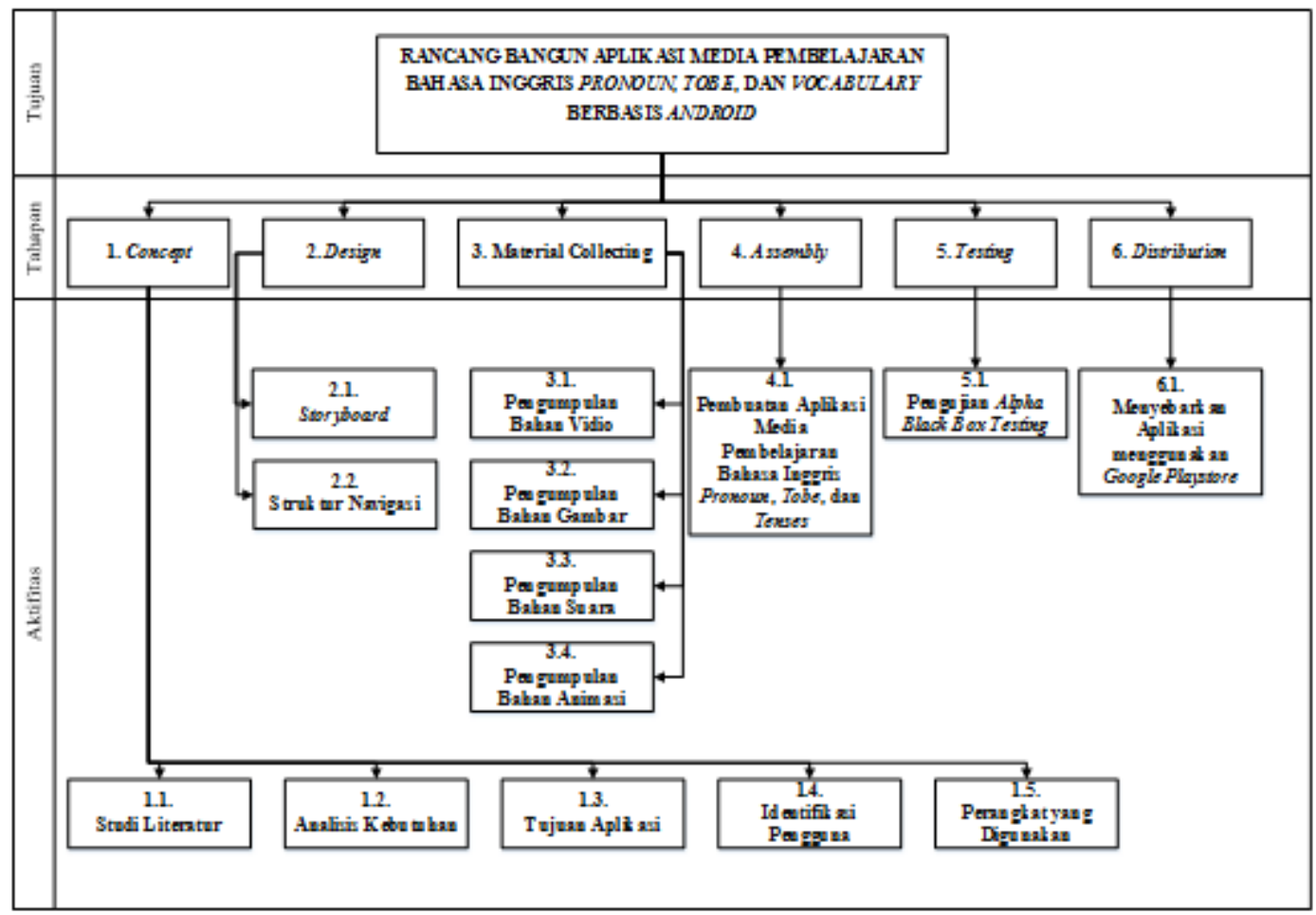

Gambar 1: Work Breakdown Structure

Penjelasan dari tahapan-tahapan pada gambar 1, ialah seperti yang tertera:

1. Concept yang menjelaskan mengenai studi literatur, analisis kebutuhan, tujuan aplikasi, identifikasi pengguna, dan perangkat yang digunakan.

2. Design yang biasanya dilakukan untuk merancang storyboard dan struktur navigasi. 
3. Material Collecting, aktifitas ini ditujukan untuk membuat atau mengumpulkan semua material yang akan dipergunakan untuk membuat aplikasi, seperti vidio, suara, animasi, dan gambar.

4. Assembly yaitu tahap penggabungan material-material yang sudah dikumpulkan pada tahap Material Collecting.

5. Testing, pada tahap ini metode pengujian alpha dengan black box testing dipilih untuk menguji aplikasi.

6. Distribution, pada tahap terakhir aplikasi akan didistribusikan melalui google play store.

\section{HASIL DAN PEMBAHASAN}

\section{A. Konsep}

Dibawah ini adalah aktivitas dari tahapan konsep, yaitu sebagai berikut:

1. Studi Literatur

Langkah kesatu adalah dilakukannya studi literatur pada buku dan jurnal. Dari studi literatur ini maka akan diperoleh data untuk menjadi acuan dalam pembuatan aplikasi.

2. Analisis Kebutuhan

Kebutuhan fungsional dari aplikasi media pembelajaran Bahasa Inggris pronoun, tobe, dan tenses berbasis android. yaitu halaman intro, halaman menu utama, dan halaman theory, halaman quiz, halaman about, halaman sources, halaman videos. Kebutuhan non fungsional dari aplikasi media pembelajaran Bahasa Inggris pronoun, tobe, dan tenses berbasis android yaitu Laptop ASUS X200CA, Intel Celeron 1.50GHz, HDD 500 GB, RAM 4096 MB, VGA Intel HD Graphics, OS Windows 8, Adobe Animate CC 2017.

3. Tujuan Aplikasi

Tujuan dari pembuatan aplikasi media pembelajaran Bahasa Inggris pronoun, tobe, dan tenses berbasis android ini adalah untuk memudahkan masyarat Indonesia dalam belajar Bahasa Inggris dimanapun dan kapanpun.

4. Identifikasi Pengguna

Dalam aplikasi ini pengguna yang direkomendasikan adalah pengguna dengan pengetahuan Bahasa Inggrisnya masih ditingkat pemula karena isi materi dari aplikasi media pembelajaran ini diperuntukan untuk kelas pemula.

5. Perangkat yang Digunakan

Aplikasi yang dibuat ini dapat digunakan di Smartphone dengan spesifikasi minimum sebagai berikut:

a. SO Android Jelly Bean 4.1.

b. RAM : 1 GB

c. $\mathrm{CPU}: 2$ Core $1.50 \mathrm{GHz}$

d. HDD : $4.1 \mathrm{~GB}$

\section{B. Desain}

Tahapan desain dilakukan untuk membuat gaya tampilan, kebutuhan material/bahan aplikasi menggunakan storyboard, dan spesifikasi mengenai arsitektur aplikasi. Tahap ini dibagi menjadi dua aktifitas yaitu:

1. Storyboard

Storyboard atau dalam bahasa Indonesia yaitu papan cerita adalah sebuah gambaran kegiatan dari aplikasi [12]. Berikut adalah gambaran skenario dari aplikasi media pembelajaran Bahasa Inggris pronoun, tobe, dan tenses berbasis android, diantaranya:

Tabel 1 : Ringkasan Storyboard

\begin{tabular}{|c|c|}
\hline Scene & Penjelasan \\
\hline Ke-I & Tampilan Intro \\
\hline Ke-II & Tampilan Home \\
\hline Ke-III & Tampilan Theory \\
\hline
\end{tabular}




\begin{tabular}{ll}
\hline \multicolumn{1}{c}{ Scene } & \multicolumn{1}{c}{ Penjelasan } \\
\hline Ke-IV & Tampilan Quiz \\
Ke-V & Tampilan About \\
Ke-VI & Tampilan Sources \\
Ke-VII & Tampilan Videos \\
\hline
\end{tabular}

\section{Struktur Navigasi}

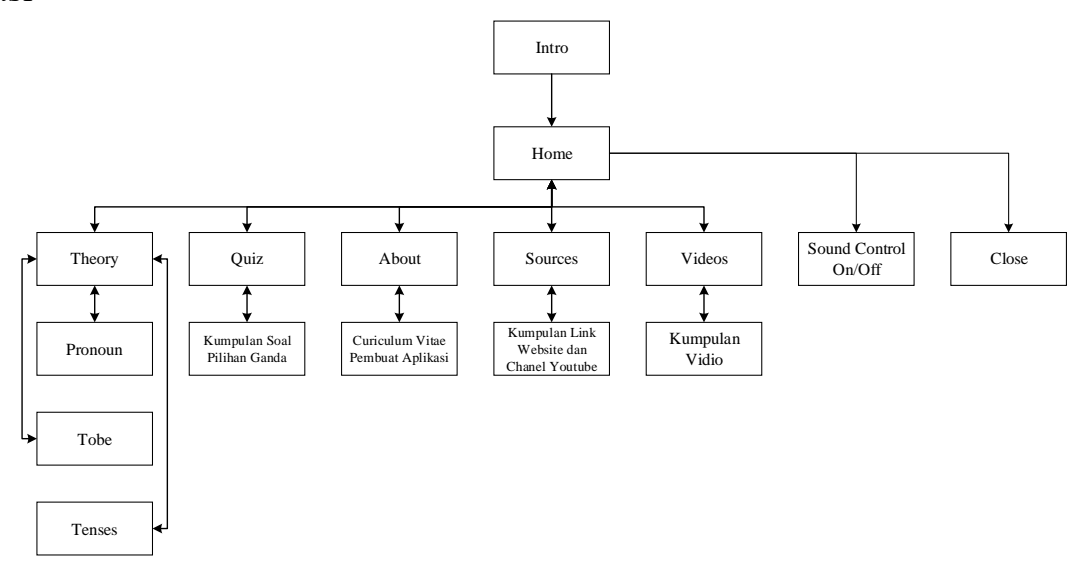

Gambar 2: Stuktur Navigasi

\section{Pengumpulan Material}

Material-material penunjang aplikasi media pembelajaran Bahasa Inggris pronoun, tobe, dan tenses akan dikumpulkan tahap ini. Material-material yang akan dikumpulkan tidak hanya material yang matang, ada juga material yang mentah yang dibuat sendiri sesuai kebutuhan. Untuk material gambar, ada beberapa gambar yang mengambil dari internet dan ada juga yang dibuat secara mandiri, untuk konten vidio dan suara semuanya mengambil dari internet, dan untuk animasi semuanya dibuat secara mandiri.

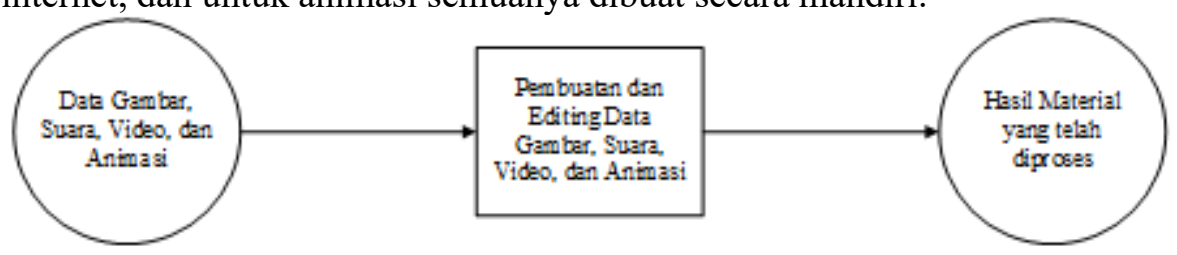

Gambar 3: Pengumpulan dan Pengolahan Data

\section{Pemasangan}

Dalam tahap pemasangan ini dilakukan untuk menggabungkan material-material yang telah dibuat dan dikumpulkan dalam tahap pengumpulan material. Material-material berupa gambar, suara, vidio, dan animasi diolah di perangkat lunak Adobe Animate CC 2017 sebagai perangkat lunak utama pembuatan aplikasi ini, berikut adalah merupakan tampilan akhir dari setiap scene yang telah dirancangan pada aktifitas storyboard, diantaranya sebagai berikut:

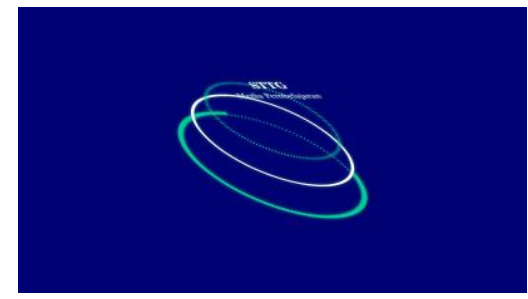

Gambar 4: Tampilan Intro

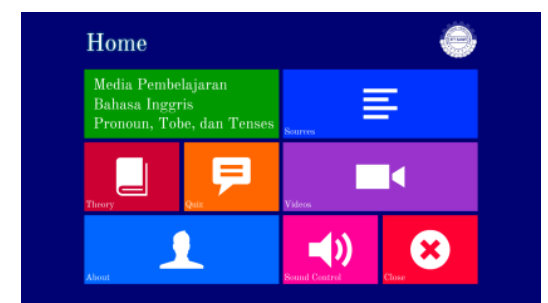

Gambar 5: Tampilan Home

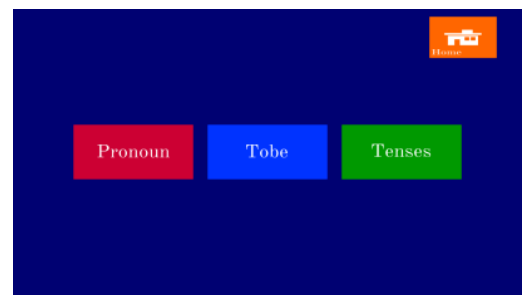

Gambar 6: Tampilan Theory 


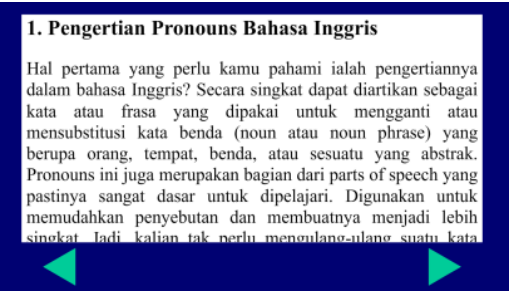

Gambar 7: Tampilan Frame Theory Pronoun/Tobe/Tenses

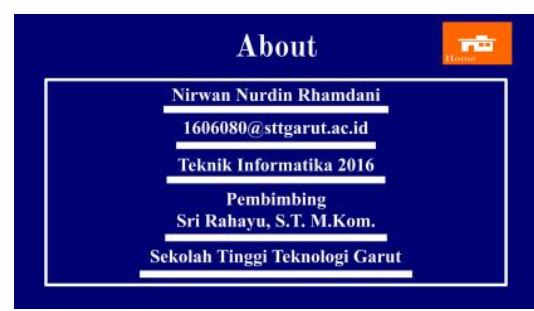

Gambar 10: Tampilan About

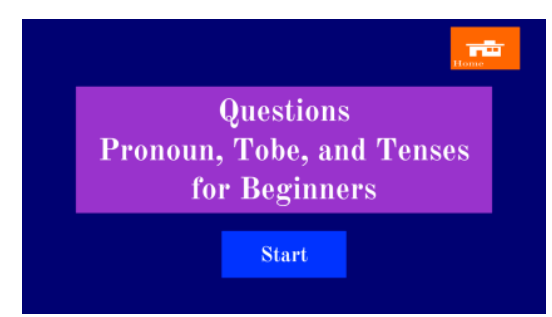

Gambar 8: Tampilan Menu Quiz

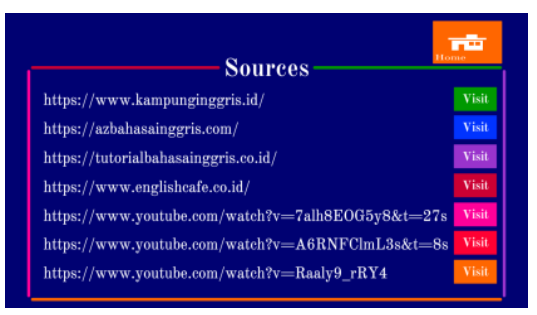

Gambar 11: Menu Sources

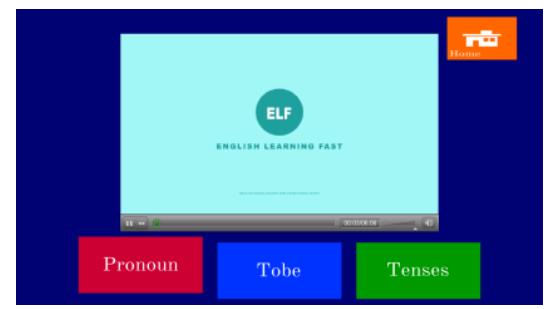

Gambar 13: Tampilan Frame Videos Pronoun/Tobe/Tenses

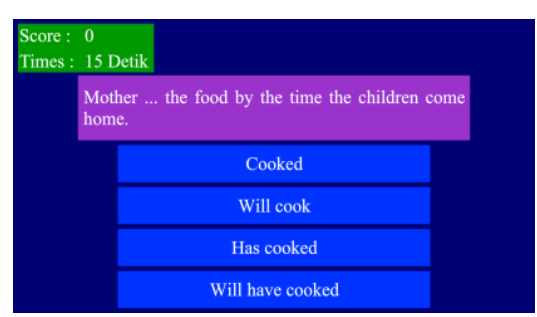

Gambar 9: Frame Quiz

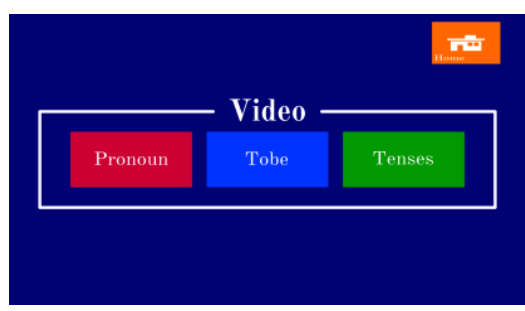

Gambar 12: Tampilan Videos

\section{E. Testing}

Pengujian alpha dengan metode black box testing dipiih dalam tahap ini, berikut merupakan hasil dari pengujian aplikasi media pembelajaran Bahasa Inggris pronoun, tobe, dan tenses berbasis android:

Tabel 2: Pengujian Alpha

\begin{tabular}{cccll}
\hline No & \multicolumn{1}{c}{ Kelas } & \multicolumn{1}{c}{ Butir } & \multicolumn{1}{c}{ Hasil } & Keterangan \\
\hline 1. & $\begin{array}{l}\text { Instalasi } \\
\text { Aplikasi }\end{array}$ & $\begin{array}{l}\text { Pemasangan } \\
\text { aplikasi pada } \\
\text { perangkat } \\
\text { smartphone }\end{array}$ & $\begin{array}{l}\text { Menginstal aplikasi ke dalam } \\
\text { smartphone }\end{array}$ & $\begin{array}{l}\text { Berjalan } \\
\text { dengan baik }\end{array}$ \\
\hline 2. & Intro & $\begin{array}{l}\text { Tampil aplikasi } \\
\text { pada layar }\end{array}$ & $\begin{array}{l}\text { Menampilkan animasi } \\
\text { loading screen, kemudian } \\
\text { masuk ke halaman menu } \\
\text { home }\end{array}$ & $\begin{array}{l}\text { Berjalan } \\
\text { dengan baik }\end{array}$ \\
\hline 3. & Halaman & Tombol Theory & $\begin{array}{l}\text { Menampilkan halaman menu } \\
\text { theory }\end{array}$ & $\begin{array}{l}\text { Berjalan } \\
\text { dengan baik }\end{array}$ \\
\hline & Tombol Quiz & $\begin{array}{l}\text { Menampilkan halaman menu } \\
\text { quiz }\end{array}$ & $\begin{array}{l}\text { Berjalan } \\
\text { dengan baik }\end{array}$ \\
\hline & Tombol About & $\begin{array}{l}\text { Menampilkan halaman menu } \\
\text { about }\end{array}$ & $\begin{array}{l}\text { Berjalan } \\
\text { dengan baik }\end{array}$ \\
\hline & Tombol Sources & $\begin{array}{l}\text { Menampilkan halaman menu } \\
\text { sources }\end{array}$ & $\begin{array}{l}\text { Berjalan } \\
\text { dengan baik }\end{array}$ \\
\hline & Tombol Videos & $\begin{array}{l}\text { Menampilkan halaman menu } \\
\text { videos }\end{array}$ & $\begin{array}{l}\text { Berjalan } \\
\text { dengan baik }\end{array}$ \\
\hline
\end{tabular}




\begin{tabular}{|c|c|c|c|c|}
\hline No & Kelas & Butir & Hasil & Keterangan \\
\hline & & $\begin{array}{l}\text { Tombol Sound } \\
\text { Control }\end{array}$ & $\begin{array}{l}\text { Menghidupkan/mematikan } \\
\text { backsound }\end{array}$ & $\begin{array}{l}\text { Berjalan } \\
\text { dengan baik }\end{array}$ \\
\hline & & Tombol Close & Menutup aplikasi & $\begin{array}{l}\text { Berjalan } \\
\text { dengan baik }\end{array}$ \\
\hline \multirow[t]{3}{*}{4.} & $\begin{array}{l}\text { Halaman } \\
\text { Menu } \\
\text { Theory }\end{array}$ & Tombol Pronoun & $\begin{array}{l}\text { Menampilkan frame pronoun } \\
\text { theory }\end{array}$ & $\begin{array}{l}\text { Berjalan } \\
\text { dengan baik }\end{array}$ \\
\hline & & Tombol Tobe & $\begin{array}{l}\text { Menampilkan frame tobe } \\
\text { theory }\end{array}$ & $\begin{array}{l}\text { Berjalan } \\
\text { dengan baik }\end{array}$ \\
\hline & & Tombol Tenses & $\begin{array}{l}\text { Menampilkan frame tenses } \\
\text { theory }\end{array}$ & $\begin{array}{l}\text { Berjalan } \\
\text { dengan baik }\end{array}$ \\
\hline 5. & $\begin{array}{l}\text { Halaman } \\
\text { Menu Quiz }\end{array}$ & Tombol Start & Menampilkan frame quiz & $\begin{array}{l}\text { Berjalan } \\
\text { dengan baik }\end{array}$ \\
\hline 6. & $\begin{array}{l}\text { Halaman } \\
\text { Menu About }\end{array}$ & curiculum vitae & $\begin{array}{l}\text { Menampilkan curiculum } \\
\text { vitae pembuat aplikasi }\end{array}$ & $\begin{array}{l}\text { Berjalan } \\
\text { dengan baik }\end{array}$ \\
\hline 7. & $\begin{array}{l}\text { Halaman } \\
\text { Menu } \\
\text { Sources }\end{array}$ & $\begin{array}{l}\text { Link-link } \\
\text { website }\end{array}$ & $\begin{array}{l}\text { Menampilkan halaman } \\
\text { website yang bersangkutan }\end{array}$ & $\begin{array}{l}\text { Berjalan } \\
\text { dengan baik }\end{array}$ \\
\hline \multirow[t]{3}{*}{8.} & $\begin{array}{l}\text { Halaman } \\
\text { Menu } \\
\text { Videos }\end{array}$ & Tombol Pronoun & $\begin{array}{l}\text { Menampilkan frame pronoun } \\
\text { videos }\end{array}$ & $\begin{array}{l}\text { Berjalan } \\
\text { dengan baik }\end{array}$ \\
\hline & & Tombol Tobe & $\begin{array}{l}\text { Menampilkan frame tobe } \\
\text { videos }\end{array}$ & $\begin{array}{l}\text { Berjalan } \\
\text { dengan baik }\end{array}$ \\
\hline & & Tombol Tenses & $\begin{array}{l}\text { Menampilkan frame tenses } \\
\text { videos }\end{array}$ & $\begin{array}{l}\text { Berjalan } \\
\text { dengan baik }\end{array}$ \\
\hline & $\begin{array}{l}\text { Tombol } \\
\text { lainnya }\end{array}$ & Tombol Next & $\begin{array}{l}\text { Menampilkan frame } \\
\text { selanjutnya }\end{array}$ & $\begin{array}{l}\text { Berjalan } \\
\text { dengan baik }\end{array}$ \\
\hline & & Tombol Back & $\begin{array}{l}\text { Menampilkan frame } \\
\text { sebelumnya }\end{array}$ & $\begin{array}{l}\text { Berjalan } \\
\text { dengan baik }\end{array}$ \\
\hline & & Tombol Home & $\begin{array}{l}\text { Menampilkan halaman menu } \\
\text { home }\end{array}$ & $\begin{array}{l}\text { Berjalan } \\
\text { dengan baik }\end{array}$ \\
\hline
\end{tabular}

\section{F. Distribusi}

Pada tahap distribusi, aplikasi media pembelajaran media pembelajaran Bahasa Inggris pronoun, tobe, dan tenses yang sudah melewati tahap pengujian dan siap untuk digunakan oleh end users. Distribusi aplikasi ini menggunakan google playstore sebagai media perantaranya.

\section{KESIMPULAN}

\section{A. Kesimpulan}

Berdasarkan hasil pembahasan mengenai rancang bangun aplikasi media pembelajaran Bahasa Inggris pronoun, tobe, dan tenses berbasis android, maka dapat disimpulkan bahwa aplikasi media pembelajaran Bahasa Inggris pronoun, tobe, dan tenses ini sudah berjalan dengan semestinya yaitu semua fitur seperti halaman theory, quiz, about, sources, dan video dalam aplikasi ini dapat berjalan dengan baik sesuai dengan apa yang diharapkan. Aplikasi ini sudah dapat diunduh di Google Playstore. 


\section{B. Saran}

Adapun saran-saran dalam penelitian ini yaitu sebagai berikut:

1. Tambahkan dubbing dalam penyampaian materi supaya pengguna dapat menerima materi tanpa melihat teks.

2. Tambahkan volume control agar pengguna dapat mengatur besar kecilnya suara.

\section{DAFTAR PUSTAKA}

[1] Fika Megawati, "Kesulitan Mahasiswa Dalam Mencapai Pembelajaran Bahasa Inggris Secara Efektif," J. Pedagog., Vol. 5, No. 9, Pp. 147-156, 2016, Doi: 10.1007/S00381-016-3174-3.

[2] V. Chairina, "Kedudukan Bahasa Inggris Sebagai Bahasa Pengantar Dalam Dunia Pendidikan," Pp. 354-364, 2019, Doi: 10.31227/Osf.Io/Xdqjg.

[3] S. N. Maili, "Bahasa Inggris Pada Sekolah Dasar :," Vol. 6, Pp. 23-28, 2018.

[4] T. Sugiharto, "Rancang Bangun Pengembangan Aplikasi Pembelajaran Bahasa Inggris Berbasis Multimedia Interaktif," Vol. 1, No. 1, Pp. 22-30, 2016.

[5] R. Masykur, N. Nofrizal, And M. Syazali, "Pengembangan Media Pembelajaran Matematika Dengan Macromedia Flash," Al-Jabar J. Pendidik. Mat., Vol. 8, No. 2, Pp. 177-186, 2017, Doi: 10.24042/Ajpm.V8i2.2014.

[6] Y. Nuriyanti And D. Tresnawati, "Pengembangan Aplikasi Pengenalan Dasar Bahasa Isyarat Sebagai Media Pembelajaran Berbasis Android," J. Algoritm., Vol. 12, No. 1, Pp. 52-60, 2015, Doi: 10.33364/Algoritma/V.12-1.52.

[7] S. Rahayu And P. Denenty, "Pengembangan Aplikasi Wudhu Dan Shalat Untuk Anak Menggunakan Sistem Multimedia," J. Algoritm., Vol. 14, No. 2, Pp. 606-612, 2015, Doi: 10.33364/Algoritma/V.142.606 .

[8] D. Tresnawati And E. Hidayat, "Pengembangan Aplikasi Pengenalan Huruf, Angka Dan Warna Untuk Anak Berbasis Multimedia," J. Algoritm., Vol. 14, No. 2, Pp. 400-409, 2015, Doi: 10.33364/Algoritma/V.14-2.400.

[9] N. R. Rambe And A. H. Saragih, "Pengembangan Media Pembelajaran Tenses Bahasa Inggris Berbasis Multimedia Interaktif Pada Siswa Sekolah Dasar," J. Teknol. Inf. Komun. Dalam Pendidik., Vol. 3, No. 2, Pp. 181-193, 2016, Doi: 10.24114/Jtikp.V3i2.5015.

[10] E. Riana And A. Gafur, "Pengembangan Multimedia Interaktif Pembelajaran Bahasa Inggris Materi Teks Deskriptif Untuk Siswa Smp/Mts,” J. Inov. Teknol. Pendidik., Vol. 2, No. 2, Pp. 212-224, 2015, Doi: $10.21831 / \mathrm{Tp} . V 2 \mathrm{i} 2.7611$.

[11] S. Rahayu And R. Ardiansyah, "Pengembangan Aplikasi Tata Cara Wudhu Dan Shalat Untuk Anak Menggunakan Sistem Multimedia," J. Algoritm., Vol. 14, No. 2, Pp. 302-308, 2016, Doi: 10.33364/Algoritma/V.14-2.606.

[12] Y. Septiana, A. Mulyani, And E. P. Dewi, "Rancang Bangun Aplikasi Edukasi Pengenalan Rafting Safety Procedure Berbasis Android," J. Algoritm., Vol. 16, No. 1, Pp. 58-65, 2019, Doi: 10.33364/Algoritma/V.16-1.58. 